\title{
ESGO contribution to the WHO initiative on elimination of cervical cancer
}

\author{
Murat Gultekin (D) , ${ }^{1}$ Philippe Morice,${ }^{2}$ Nicole Concin, ${ }^{3}$ Denis Querleu ${ }^{4}$
}

\begin{abstract}
${ }^{1}$ Department of Obstetrics and Gynecology, Division of Gynecological Oncology, Hacettepe Universitesi, Ankara, Turkey

${ }^{2}$ Department of Surgery, Gustave Roussy, Villejuif, Île-deFrance, France

${ }^{3}$ Department of Gynecology and Obstetrics; Innsbruck Medical Univeristy, Innsbruck, Austria ${ }^{4}$ Department of Surgery, Institut Bergonie, Bordeaux, France
\end{abstract}

\section{Correspondence to} Dr Murat Gultekin, Department of Obstetrics and Gynecology, Division of Gynecological Oncology, Hacettepe Universitesi, Ankara 4 000, Turkey; mrtgultekin@yahoo. com

Accepted 4 February 2020 Published Online First 2 March 2020

\section{Sinked}

- http://dx.doi.org/10.1136/ ijgc-2020-001285

Check for updates

(C) IGCS and ESGO 2020. № commercial re-use. See rights and permissions. Published by BMJ.

To cite: Gultekin M, Morice $\mathrm{P}$, Concin N, et al. Int J Gynecol Cancer 2020;30:434-435.
As a society of actions, the European Society of Gynaecological Oncology (ESGO) has declared a strong and solid campaign against cervical cancer.

Management of cervical cancer, which meets the standards, remains a major objective. ESGO has developed a set of documents, all available on the eAcademy portal, which aim to guide physicians and all healthcare providers. Specifically, the ESGO guidelines for the management of cervical cancer were developed in 2018, in collaboration with the European Society for Radiotherapy (ESTRO) and the European Society of Pathology (ESP). In accordance with our development process for guidelines, the cervical cancer guidelines were developed by a multidisciplinary geographically balanced group of experts, and submitted for review to ESGO members from many countries, to ensure that optimal guidelines are applicable in all parts of Europe. The guidelines have been jointly published in three journals (International Journal of Gynecological Cancers, Radiotherapy and Oncology, and European Journal of Pathology), printed in booklets, translated into several European languages (including Portuguese, Spanish, Italian, Russian, and Arabic). ${ }^{1}$ They are freely available on the ESGO guidelines smartphone applications. ESGO, ESTR0, and ESP jointly agreed on regular updates of these guidelines, and the launch of the first update is planned for the ESGO 2020 State of the Art Conference in Copenhagen, Denmark.

In addition, in January 2020, ESGO published the ESGO quality indicators for surgical treatment of cervical cancer in the International Journal of Gynecological Cancer. ${ }^{2}$ A new educational activity that took place, in cooperation with ESTRO, was an advanced course on 'Management of locally advanced cervical cancer: from guidelines to practical management'. The course featured an overview of evidence-based theory combined with live transmission of surgery and demonstration of brachytherapy manual skills, and was held for the first time in January 2020.

ESGO has decided not to take sides in the controversy on the use of minimally invasive surgery deriving from the the Laparoscopic Approach to Cervical Cancer (LACC) study. ${ }^{3}$ The revised ESGO guidelines propose open surgery as the 'gold standard', but recommend minimally invasive surgery in appropriately counseled patients. In addition, ESGO is currently conducting a pan-European retrospective study led by Dr Luis Chiva, which may clarify the role of specific precautions in preventing recurrences related to the misuse of minimally invasive surgery. ${ }^{4}$

In the field of cervical cancer prevention, ESGO has set up a prevention committee with well known experts. In cooperation with the European Federation of Colposcopy (EFC), a joint position paper on vaccination has been published, with free access on PubMed to all members. ${ }^{5}$ The next steps planned for 2020 include an ESGO-EFC joint statement on cervical cancer screening; a meta-analysis by Marc Arbyn on triage of HPV-positive cases, funded by ESGO; and a systematic review on how to evaluate cone biopsy specimens conducted by Dr Maria Kyrgiou, funded by ESGO and a number of other societies. Recently, prevention task force members have developed a new Horizon 2020 Project grant to create a new riskstratified cervical cancer screening guideline project. By 2020, ESG0 will also lead a European Parliamentary Forum for Sexual and Reproductive Rights to advocate a pan-European policy for vaccination and screening. In addition, ESG0 and the European CanCer Organisation (ECCO) have led a pan-European cancer societies statement and HPV elimination European Union action plan, which was launched in December 2019 at the European Union parliament. ${ }^{6}$

ESGO believes strongly in taking an advocacy role and raising awareness about the prevention of gynecological cancers. ESGO generates the science and has an effect on a growing global population and policy makers through European Network of Gynaecological Cancer Advocacy Groups (ENGAGe), an elaborate network of cancer survivors and advocates.

As an example, ESGO-ENGAGe released, in language for lay people, a set of cancer fact sheets, and leaflets on HPV vaccines and cervical cancer screening, which were translated into 10 languages. All ENGAGe products are available for free download at the ENGAGe website and the local advocacy websites. ESGO members and hospitals can print and use these for their patients.

The European Network of Young Gynecological Cancers (ENYGO), a group of young gynecological oncologists, is enthusiastically playing its part with a 
number of actions. For example, the bike ride, Ride4Women, led by Rene Laky, a repetitive awareness event, with the complete support of ESGO, crossed many Eastern European countries, where the incidence of cervical cancer is highest in Europe. By 2019 they had crossed the Balkans, drawing attention of the public, media, and politicians to the acute need to act against cervical cancer and its precursors.

All these actions are in line with WHO. The WHO is conducting a global action plan, with the ambitious goal of eliminating cervical cancer through HPV vaccination for every young girl on the planet, and through the screening and treatment of pre-cancerous lesions in women over the age of 30 . WHO also aims at improving access to diagnosis and treatment of invasive disease, an initiative which may also improve the quality of care of patients who have not had vaccination and screening. ESGO is actively contributing to this substantial and unprecedented effort. Dr Murat Gultekin attended a meeting of WHO consultation on increased access to screening and treatment, which led to ESGO's involvement in developing WHO's road map of activities. ESGO will be continuously involved in the technical support of WHO and countries implementing the screening program, particularly in the European area defined by WHO. Dr Denis Querleu attended in 2019 a consultation meeting to develop a technical package on the management of cervical cancer, where he facilitated a discussion on monitoring of early diagnosis and treatment and quality of care indicators, a topic with which ESGO has extensive experience.

The revised International Federation of Gynecology and Obstetrics (FIGO) staging for cervical carcinoma was officially published in January 2019, and has led to improvements in the classification and management of patients with cervical cancer. The FIGO committee accepted the input of gynecological cancer societies, including ESGO. Finally, ESGO has given a WHO representative the opportunity to present the WHO program to 38 presidents of European national societies of gynecologic oncology, from Ireland to Kazakhstan, at the second summit of the presidents, an event which will be repeated at the time of each ESGO meeting and State of the Art symposium.

This extensive list of pro-active actions places ESGO at the front line in the battle against cervical cancer. However, the values of a team of dedicated individuals rely on the action of its members. This manuscript is a summary of our coordinated strategic action against cervical cancer, but it is also a call for everyone to aim at improving the quality of care for each patient, to put into practice cost-effective screening, and to strive tirelessly against inaccurate campaigns against HPV vaccinations often seen in newspapers and social media.

Acknowledgements We thank all of our partners in our fight against cervical cancer-namely, the International Federation of Gynecology and Obstetrics (FIGO), European Society for Radiotherapy (ESTRO), European Society of Medical Oncology (ESM0), European Society of Pathology (ESP), European CanCer Organisation (ECCO), European Federation of Colposcopy (EFC), European Parlimentary Forum (EPF), European Network of Young Gynaecological Oncologists (ENYGO), European Network of Gynaecological Oncological Trial Groups (ENGOT), European Network of Gynaecological Cancer Advocacy Groups (ENGAGe), and the European societies of gynaecological oncology. We are together and working for the future to lend a hand of support to the outstanding initiatives against cervical cancer and to do our very best to aid the WHO

Contributors The authors have contributed equally to the paper given by their positions in the ESGO Council and summarised their activities upon different aspects of cervical cancer control. NC has summarised the guidelines, MG has summarised prevention and ENGAGe activiites, PM has summarised cervical cancer workshops and SUCCOR studies, and finally, DQ has summarised the rest with ENYGO, EU, and ECCO activities.

Funding The authors have not declared a specific grant for this research from any funding agency in the public, commercial or not-for-profit sectors.

Competing interests None declared.

Patient consent for publication Not required.

Provenance and peer review Not commissioned; externally peer reviewed.

ORCID iD

Murat Gultekin http://orcid.org/0000-0002-4221-4459

\section{REFERENCES}

1 Cibula D, Pötter R, Planchamp F, et al. The European Society of Gynaecological Oncology/European Society for Radiotherapy and Oncology/European Society of Pathology guidelines for the management of patients with cervical cancer. Int J Gynecol Cancer 2018;28:641-55.

2 Cibula D, Planchamp F, Fischerova D, et al. European Society of Gynaecological Oncology quality indicators for surgical treatment of cervical cancer. Int J Gynecol Cancer 2020;30:3-14.

3 Querleu D, Cibula D, Concin N, et al. Laparoscopic radical hysterectomy: a European Society of Gynaecological Oncology (ESGO) statement. Int J Gynecol Cancer 2020;30:15

4 Chiva L, Zanagnolo V, Kucukmetin A, et al. An international European cohort observational study comparing minimally invasive surgery versus open abdominal radical hysterectomy in patients with stage IB1 cervical cancer operated in 2013-2. Oral communication, ESGO Athens Meeting, 2019.

5 Joura EA, Kyrgiou M, Bosch FX, et al. Human papillomavirus vaccination: the ESGO-EFC position paper of the European Society of Gynaecologic Oncology and the European Federation for Colposcopy. Eur J Cancer 2019;116:21-6.

6 ECCO 2019 European Cancer Summit - Resolution on HPV, 2019. Available: https://www.ecco-org.eu/ECCO2019Summit/Resolutions/ HPV [Accessed 21 February 2020]. 